\title{
Chapter 3 \\ Molecular-Based Techniques for the Study of Microbial Communities in Artworks
}

\author{
Katja Sterflinger and Guadalupe Piñar
}

\begin{abstract}
Thanks to the revolutionary invention of the polymerase chain reaction and the sequencing of DNA and RNA by means of "Sanger sequencing" in the 1970th and 1980th, it became possible to detect microorganisms in art and cultural assets that do not grow on culture media or that are non-viable. The following generation of sequencing systems (next generation sequencing, NGS) already allowed the detection of microbial communities on objects without the intermediate step of cloning, but still most of the NGS technologies used for the study of microbial communities in objects of art rely on "target sequencing" linked to the selectivity of the primers used for amplification. Today, with the third generation of sequencing technology, whole genome and metagenome sequencing is possible, allowing the detection of taxonomic units of all domains and kingdoms as well as functional genes in the produced metagenome. Currently, Nanopore sequencing technology is a good, affordable, and simple way to characterize microbial communities, especially in the field of Heritage Science. It also has the advantage that a bioinformatic analysis can be performed automatically. In addition to genomics and metagenomics, other "-omics" techniques such as transcriptomics, proteomics, and metabolomics have a great potential for the study of processes in art and cultural heritage, but are still in their infancy as far as their application in this field is concerned.
\end{abstract}

Keywords Biodeterioration $\cdot$ Cultural heritage $\cdot$ Microbiology $\cdot$ Next generation sequencing $\cdot$ Metagenomics $\cdot$ Microbial pedigree $\cdot$-Omic technologies $\cdot$ Nanopore sequencing

K. Sterflinger $(\bowtie) \cdot$ G. Piñar

Institute of Natural Sciences and Technology in the Arts, Academy of Fine Arts Vienna, Vienna, Austria

e-mail: k.sterflinger@akbild.ac.at; g.pinarlarrubia@akbild.ac.at 


\section{Introduction}

Works of art, including modern and historical paintings, murals, sculptures made of various materials, architectural surfaces, books, and depot material are colonized and destroyed by microorganisms under suitable conditions (Koestler et al. 2003). Object surfaces in combination with their corresponding environment are in most cases an extreme habitat for microorganisms: In the open air, the microbial community is influenced by UV radiation, changing humidity, and dehydration as well as nutrient deficiency. Indoors, the main problem for the organisms is the low availability of water. On wall surfaces, osmotic stress is caused by salt contamination, and layers of paint can even be toxic due to lead or zinc additives. Accordingly, works of art contain microbial communities that can be classified as stress-tolerantextremotolerant - or even stress-loving-extremophilic. Thus, osmotic sites are often dominated by halophilic bacteria and archaea, which are recognizable as an ecological group by their characteristic pink coloration, but for the most part are unable to grow on culture media (Ettenauer et al. 2014); halotolerant and xerotolerant fungi also occur and are often overgrown by rapidly growing transients on culture media and thus not noticed (Sterflinger et al. 2018a). Contemporary materials, e.g. PVC, PE, PLA are colonized and decomposed by highly specialized bacteria and fungi, which in turn do not grow easily on ordinary laboratory media (Fig. 3.1).

Extremotolerant and extremophilic organisms have very specific growth requirements, which can often only be simulated to a limited extent or not at all in the laboratory and with conventional culture media. What has long been known and accepted in general environmental microbiology, therefore, also applies to microorganisms in artifacts and cultural objects: only a small part of the microorganisms can be detected by sampling and enrichment on culture media, the majority of the microflora remains undetected with these classical microbiological enrichment techniques (Amann et al. 1995). Accordingly, until a few decades ago, information on

Fig. 3.1 Seiko Mikami, The World Memorable: Suitcases (1993);

"Radioactive Waste Bags," all the suitcase shows growth of the xerophilic fungus Aspergillus restrictus, which is often overseen in culture media approaches due to its slow growth (the installation consists of three suitcase "Suitcase Accident Air Noxious Particles Waste Containers" and "Biohazard Autoclave Bags" that are not shown here)

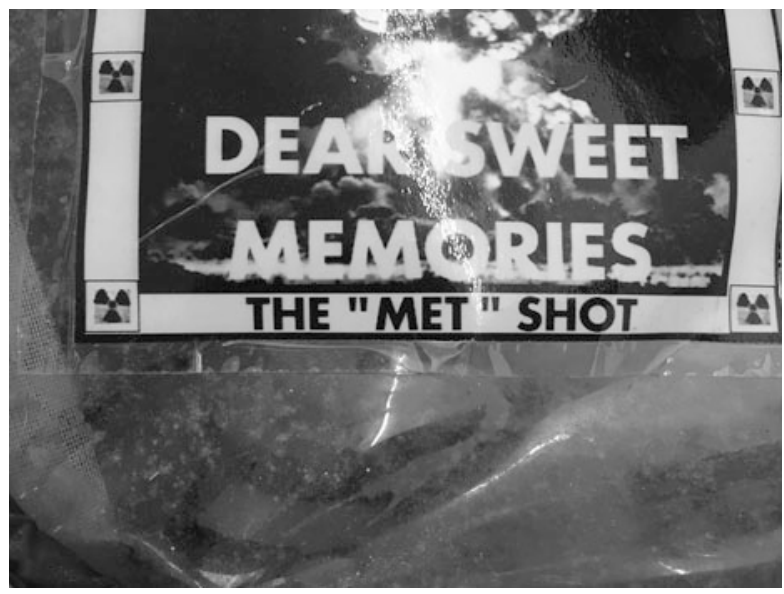


microbial biodiversity was limited, but also the knowledge about the ecology of organisms and the processes of damage they cause.

Only the routine use of PCR in the 1980s and 1990s made it possible to use microbial DNA for research on biogenic damage processes on art and cultural assets in order to overcome the hurdle of cultivation and enrichment and to complete and expand the data obtained from this. Initially, in addition to cloning and Sanger sequencing (which is considered a first-generation sequencing technology developed by Frederick Sanger and colleagues in 1977), DNA-based fingerprinting techniques were successfully used to study the biological agents that cause the biodeterioration of cultural artifacts.

Denaturing gradient gel electrophoresis (DGGE) in combination with clone libraries and first-generation sequencing of amplified DNA fragments has been successfully used to characterize microbial communities on walls and murals, paper, parchment, glass, stone, textiles, human remains, and other materials of cultural heritage (Rölleke et al. 1999; Schabereiter-Gurtner et al. 2001, 2002a, b; Laiz et al. 2003; Di Bonaventura et al. 2003; Saiz-Jimenez 2003). The application of this molecular strategy, together with imaging and chemical analyses (Pinzari et al. 2010; Wiesinger 2018), has provided relevant information on the microbial communities associated with different materials and the microbiological risk they present on the surface of the substrates studied (Sterflinger and Piñar 2013). In addition, such studies have enabled the implementation of preservative and disinfectant treatments as well as the monitoring during and after the conservation treatment of valuable objects (Jroundi et al. 2015).

Although first-generation sequencing technology provided only limited data, the first studies opened a new door into the world of biodiversity of artifacts and cultural assets and into the phylogeny of the organisms involved. These studies also led to the description of new species involved in biodeterioration (Sterflinger et al. 1997; Wieser et al. 2005). The studies were also an important basis-and justificationfor the further development and application of technologies in the field of Heritage Science. Nevertheless, the work based on DNA-fingerprints, clone libraries, and first-generation sequencing was rather time-consuming and not free of errors, since the selection of suitable primers for DNA amplification already resulted in a strong selection of the initial data. Since Sanger sequencing was only able to sequence short parts of the total DNA contained in a cell in a reasonable time and with reasonable effort, the studies were limited to taxonomically and phylogenetically relevant DNA sections such as 16S-, 18S-rDNA, and ITS sequences. This provided information on biodiversity, but not on the potential of functional genes in potentially harmful organisms. To establish a link between the identity of an organism and its function was, once again, only possible by means of experiments on pure cultures, if available. 


\section{High-Throughput Sequencing Methods: Next Generation Sequencing (NGS)}

"The commercial launch of the first massively parallel pyrosequencing platform in 2005 ushered in the new era of high-throughput genomic analysis now referred to as next-generation sequencing (NGS)" (Völkerding et al. 2009). Although these technologies generate shorter reads (between 25 and $500 \mathrm{bp}$ ), they are capable of delivering many hundreds of thousands or millions of reads in a relatively short time (a few hours). This leads to a high coverage, but the assembly process is much more computationally intensive. These technologies are far superior to Sanger sequencing due to the high data volume and the relatively short time required to sequence an entire genome (Metzker 2010). In recent years, the so-called next generation sequencing technologies (NGS) have been developed and have been a revolutionary innovation for deciphering the complexity of genomes and metagenomes. NGS methods have enabled significant advances, such as the preparation of NGS libraries in a cell-free system without cloning; the thousands to many millions of sequencing reactions produced in parallel; and direct sequencing output that is performed cyclically and in parallel. The large number of reads generated by NGS enables the sequencing of entire genomes and metagenomes at an unprecedented speed. Today, there are several sequencing platforms based on different technologies (Goodwin et al. 2016). Therefore, the choice of the sequencing platform to be used for a particular study depends on the requirements and resources, which vary depending on the type of sample, study finality, cost/runtime, data output, tolerated amplicon size, data storage capacities, and error rates.

Different methods available on the market until 2009 are explained in detail by Völkerding et al. (2009); the most relevant ones are only briefly described here:

- The Roche 454 technology was derived from the technological convergence of pyrosequencing and emulsion PCR. The system has been efficiently used both for sequencing the entire genome and for amplicon sequencing in environmental and medical studies. However, the technology was no longer competitive and was discontinued in 2013.

- Illumina/Solexa: In 2006, the Solexa Genome Analyzer, the first "short-read" sequencing platform, was commercially launched. Acquired by Illumina in 2006, the Genome Analyzer uses a flow-through cell consisting of an optically transparent slide with individual lanes on whose surface oligonucleotide anchors are bound. The template DNA is fragmented into lengths of several hundred base pairs and finally repaired to produce $5^{\prime}$-phosphorylated blunt ends. The polymerase activity of the Klenow fragment is used to attach a single A base to the $3^{\prime}$ end of the blunt phosphorylated DNA fragments. This addition prepares the DNA fragments for ligation to oligonucleotide adapters that have a single T-base overhang at their $3^{\prime}$ end to increase ligation efficiency. The adapter oligonucleotides are complementary to the flow cell anchors. Under boundary dilution conditions, adapter-modified single-stranded template DNA is added to the 
flow cell and immobilized on the anchors by hybridization. Currently, Illumina is one of the most widely used sequencing systems both in science and clinical applications.

- The SOLiD (Supported Oligonucleotide Ligation and Detection) System 2.0 platform, marketed by Applied Biosystems, is a ligation-based short-read sequencing technology. Applied Biosystems has refined the technology and in 2007 launched the SOLiD instrumentation. Sample preparation is similar to the 454 technology in that DNA fragments are ligated to oligonucleotide adapters, bound to beads, and clonally amplified using emulsion PCR.

Recent technologies developed during the last decade are:

- The next generation sequencing technology of Ion Torrent (ThermoFisher) is not based on an optical detection system. The technology was first published in Nature in 2011 (Rothberg et al. 2011) and was launched on the market in 2012. It exploits the fact that the addition of a dNTP to a DNA polymer releases a hydrogen ion. The $\mathrm{pH}$ change resulting from these hydrogen ions is measured using semiconductors, with the simultaneous measurement of millions of such changes determining the sequence of each fragment.

- Single Molecule, Real-Time (SMRT) sequencing (Pacific Biosciences) is the core technology that enables sequencing long reads with resulting reads of several tens of kilobases in length. Due to the long fragments, the technology is particularly useful for de novo sequencing and the assembly of entire genomes (Eid et al. 2009).

- Nanopore sequencing technology (Oxford Nanopore Technologies) is based on reading the inserted nucleotides while the DNA sequence passes through a nanopore with an inner diameter of $1 \mathrm{~nm}$ (Branton et al. 2008). The electrical conductivity of the protein nanopore is changed as the DNA passes through, and a signal is detected in this way. Sequencing with this innovative technology does not necessarily require intermediate PCR amplification or chemical labeling. In addition, this technology offers a pocket-sized sensor device (Fig. 3.2), the MinION, which was made commercially available in 2015 and whose performance has been further optimized in recent years, resulting in an increasing number of publications in the field of metagenomics.

\section{Metagenomics in Cultural Heritage}

Metagenomics can be performed by the "Sequence it all" approach (simple reading of all DNA sequences present in a sample) or by the "Target sequencing" approach, concentrating on certain conserved sequences, such as only ribosomal RNA genes. The latter procedure has several advantages, such as reducing the complexity of the data obtained and the possibility of assigning more sequences to a particular organism or a group of related organisms. This approach facilitates some 
Fig. 3.2 Nanopore sequencing device containing a flow cell with protein pores. For size comparison a $2 \mathrm{ml}$ cap is shown

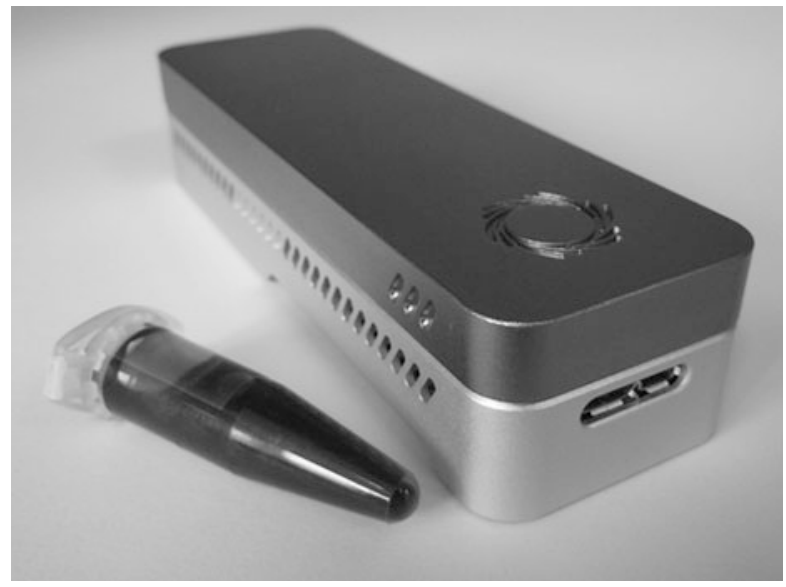

semi-quantitative analyses, which is much more difficult in the analysis of all sequences composed of many organisms with largely different genome sizes.

The 16S rRNA gene and ITS regions are the most frequently sequenced regions when using NGS for the examination of art objects (Piñar et al. 2019). This approach is useful in the field of cultural heritage, as DNA of poor quality or low concentration can be amplified by using degenerate primers and PCR. Therefore, metagenomics using NGS analysis has been widely used to analyze the microbial colonization of ancient monuments and valuable objects. Several publications refer to NGS analyses used for biological diagnosis of cultural heritage. Some examples focus on stone monuments (Cutler et al. 2013), murals (Rosado et al. 2014), construction materials of historic buildings (Adamiak et al. 2018), and tombs (Huang et al. 2017). These methods are powerful, but as with any PCR-based method, the primers selection and/or the exponential amplification will distort the results. Furthermore, the quantification of the relative abundance of all different domains of life present in a sample is not possible.

The technological development of molecular methods in recent years has overcome many technical obstacles that have existed up to now. Third-generation sequencing technologies are still under development, but already offer some advantages over second-generation sequencing platforms. The third generation of highthroughput sequencing technologies offers an intelligent solution to the limitations of previous technologies (Schadt et al. 2010). Instead of sequencing a clonally amplified template, a single DNA template is sequenced, leading to a reduction in the use of reagents and chemicals as well as to simplified protocols and miniaturization of the entire technical process and equipment.

Although NGS technologies are not entirely without flaws and limitations (Sterflinger et al. 2018b), the amazing development and establishment of NGS techniques in the field of cultural heritage offers a powerful DNA-based approach for the analysis of valuable artifacts. In addition, the generated data provide 
information to answer many interesting questions that can arise when handling valuable art objects and might help to:

- provide insight into the selection of materials at the time of manufacture, such as the composition of the materials,

- gain knowledge about the storage conditions of materials and their geographical origin,

- trace the history of use of the object, and

- group objects of unknown origin on the basis of similarities in their microbiomes.

The information enables to understand many open questions in a variety of fields, such as archeology, history, restoration, philology, or criminology, but also can contribute to give a historical benefit to the investigated objects (Piñar et al. 2019).

As described above, there are different sequencing platforms based on different technologies. All of them present advantages and disadvantages; therefore, the choice of the sequencing platform should be decided carefully depending on the purpose of the study. Also, the bioinformatics tools and pipelines necessary for data analysis are manifold and have to be chosen according to the respective data sets and the scientific question to be answered. In recent years, different methods have been tested, their protocols optimized and used to perform metagenomic analyses on artworks at the first time. The following three case studies describe the application of three different sequencing technologies for the study of cultural assets, but with different finalities: (1) Ion Torrent technology, (2) Illumina technology, and (3) Nanopore technology.

(1) Ion Torrent technology. In a metagenome study performed on three ancient marble statues, the main question was whether they might have been smuggled and/or stored together and whether biological traces could help to elucidate their geographical origin (Piñar et al. 2019). Two statues were human torsi, one female and one male, and the third one was a representation of a small girl's head (Fig. 3.3). The finality of this study was to collect as much biological information as possible from the surface of the statues to answer the aforementioned questions. To this end, metagenomic analyses were performed using the Ion Torrent sequencing technology by means of the Ion Personal Genome Machine (PGM), which allows a very good target barcoding sequencing of different life domains. Especially for the screening of prokaryotes, this technology offers a very smart solution thanks to the commercialization of the Ion $16 \mathrm{~S}$ rDNA Metagenomics Kit that enables the simultaneous targeting of seven of the nine variable regions of the $16 \mathrm{~S}$ rDNA. This eliminates the bias committed by other NGS technologies that tend to focus only on the V4 region of the $16 \mathrm{~S}$ rDNA, which even if the most widely used does not cover all phylogenetic groups (Piñar et al. 2019). To approach this study, the deposits and dirt visible in the spaces (e.g., folds, curls of hair) defined by the shape of the sculptures were removed with the help of sterile scalpels and needles without damaging the rock itself. The material contained was mainly powder, dust, dirt, and even some textile fibers. 


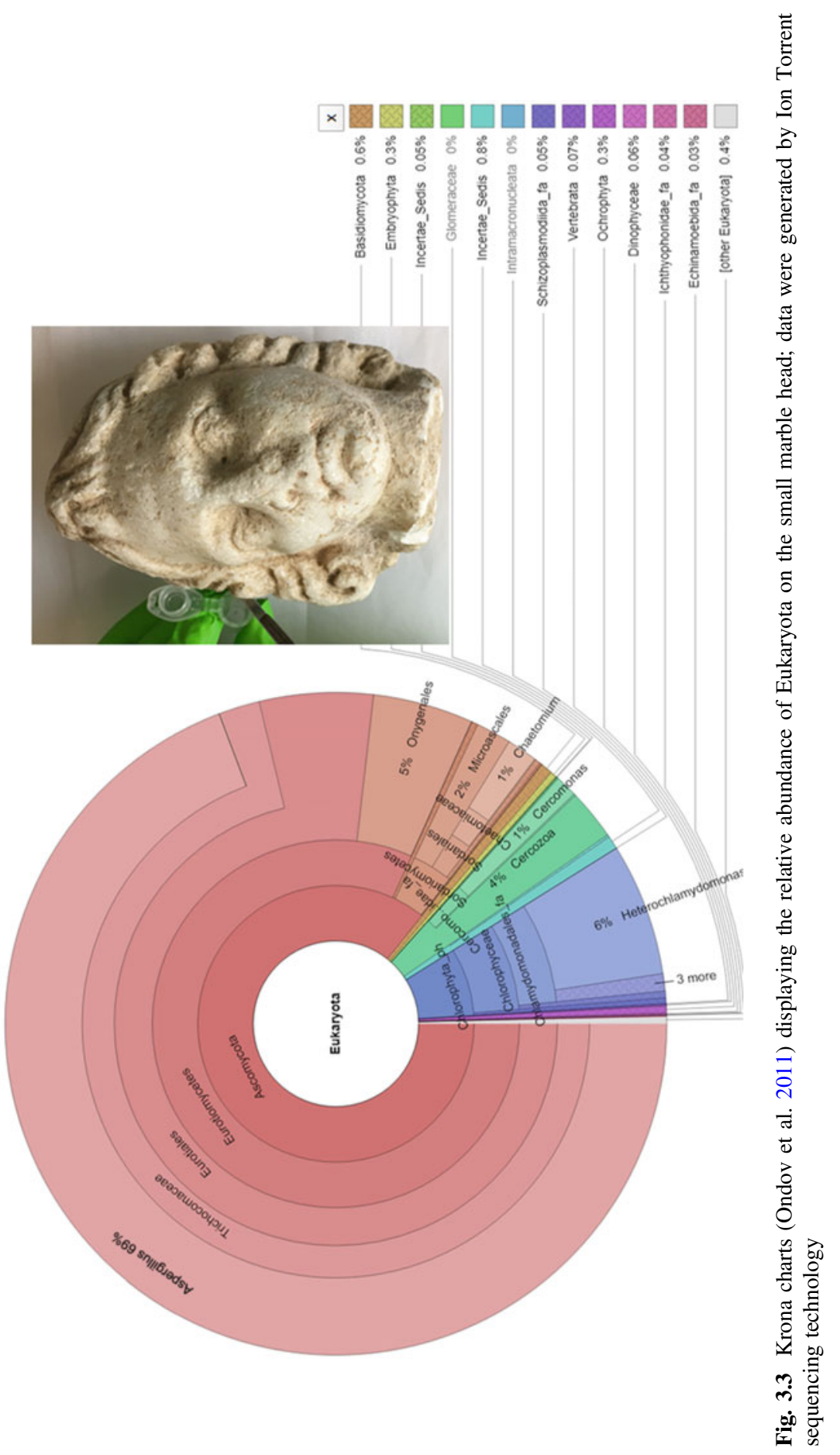


The samples taken from the same statue were later pooled for DNA extraction analysis to perform a single DNA extraction per statue. Since the DNA quantities extracted from the samples were not high enough to directly produce a library (the Ion Torrent technology requires a quantity of $10 \mathrm{ng} / \mu \mathrm{l}$ DNA as input), a genetic strategy, comprising analyses of the $16 \mathrm{~S}$ ribosomal DNA (rDNA) of prokaryotes (Ion 16S Metagenomics Kit: primer set V2-4-8 and primer set $\mathrm{V} 3-6,7-9$ ), the $18 \mathrm{~S}$ rDNA of eukaryotes (targeting the $\mathrm{V} 4$ region with primers $528 \mathrm{~F} / 706 \mathrm{R}$ ) as well as the internal transcribed spacer regions of fungi (targeting the ITS1 region) was performed. The resulting DNA libraries were barcoded and pooled onto two DNA chips, whose sequencing runs provided an average of more than 4,250,000 total readings with an average unique reading length of 200-300 bp. It is important to note that in the case of the Ion Torren system, the output is a FastQ file and the sequence processing and data mining must be carried out by a bioinformatician. In this study, the raw data were trimmed, filtered, and compared with different databases using a variety of bioinformatics pipelines. After trimming (Martin 2011) only reads longer than $100 \mathrm{nt}$ and containing at least one primer were retained. The prokaryotic reads were initially grouped based on their hypervariable region of origin (HVR). The HVR was derived by a cmscan (Nawrocki and Eddy 2013) with the prokaryotic 16S rRNA model of Rfam (Kalvari et al. 2018) at each read and the start and end position of agreement was compared with the correlating HVR position in the Rfam model. Measured values that were mapped outside the HVR model were discarded, while the other measured values were cut and filtered with Cutadapt similar to the eukaryotic and fungal measured values. The taxonomy was assigned with DADA based on the protocol published in Callahan et al. (2016). For the prokaryotic values, the protocol was applied to each group of IHR separately and to all HVR simultaneously. The results of this study showed to be suitable to draw some conclusions about a possible relationship between the two marble torsi; their microbiomes showed similarities involving many soildwelling organisms, which may indicate storage or burial in agricultural land or even pasture soil. For the male torso, it was even possible to deduce a geographical origin, as DNA traces of Taiwania, a tree of the cypress family found only in Taiwan and the south of the PRC, were present. In contrast, the statue of the young girl's head showed a more specific microbiome with an abundance of organisms of marine origin, which gives rise to the suspicion that this statue was in contact with the sea. Although the amount of data derived from this method is very large, one must be aware that the amplification step at the beginning of the procedure, targeting specific DNA regions, is a possible bias of the method as it is selective both in terms of taxonomic units and their quantification. Nevertheless, in this study and in the case of the analysis of prokaryotes, this bias was minimized by targeting most of the variable regions of the $16 \mathrm{~S}$ rDNA simultaneously.

(2) Illumina Technology: Another important application of molecular analysis in cultural heritage research is biocodicology (Fiddyment et al. 2019). A study carried out by Piñar et al. on ancient parchment writings provides an example of 
the emerging field of research in biocodicology and shows how metagenomics can help to answer relevant questions that can contribute to a better understanding of the history of ancient manuscripts (Miklas et al. 2019; Piñar et al. 2020c). For this purpose, two Slavonic codices from the eleventh century were investigated by shotgun metagenomics using the Illumina sequencing platform.

The analysis of nucleic acids contained in historical parchments is a difficult matter due to the poor preservation of ancient DNA (aDNA) and the frequent external contamination with modern DNA (Vuissoz et al. 2007). A crucial step in such studies is the extraction of DNA from very little sample material (a few fibers or 1 to 2 millimeters of material) and even from eraser fragments loosened after rubbing the parchment surface (Fiddyment et al. 2019). In the case-study presented here, a combination of two commercial kits was used for the successful extraction of total DNA (ancient and modern), which aim at a silica membrane-based purification of very short DNA fragments $(\sim 70 \mathrm{bp})$, i.e. the expected size of the ancient DNA. This approach further enables the elution in very small volumes allowing the concentration of very low DNA yield, as it was the case of the DNA extracted from these ancient objects. The DNA extracts were used to create DNA libraries with the NEBNext Ultra II DNA Library Prep Kit for Illumina and sequenced by means of the Illumina HiSeq 2500 platform using $100 \mathrm{bp}$ single reads. The total number of reads processed ranged from $43,150,589$ to $50,416,907$, with reads being significantly shorter than when using Ion Torrent or Nanopore. However, the strategy followed in this study showed to be adequate for analyzing the ancient DNA of the parchments. The application of Illumina shotgun sequencing proved to be very effective for the sequencing of short DNA fragments (aDNA) with a high sensitivity, generating a huge amount of data and being less susceptible to chimeric artifacts that can result from PCR-based analyses. Quality control of the reads was done with fastqc (Andrews 2010). Cutadapt was used to trim adapter sequences (Martin 2011). FastQ Screen was used to assess the origin of the parchment probes (Wingett and Andrews 2018). The parchment metagenomes were assessed by first removing human and animal reads for each dataset. This was done for each experiment by filtering out the reads to the human and corresponding animal genomes with STAR (Dobin et al. 2013). The remaining reads were then processed with MetaphlAn2 in order to describe and represent the microbiomes of the parchment probes (Truong et al. 2015). The endogenous DNA enabled to infer the animal origin of the skins used in the production of the two codices, while the DNA obtained from viruses provided insights into the plant origin of the inks used in one of the two codices. In addition, the microbiomes colonizing the surface of the parchments helped to determine their state of preservation and their latent risk of deterioration. The advantage of using this molecular strategy was the detection of extremely small DNA fragments that originate from already strongly degraded ancient DNA, which could not be detected by technologies with longer reading lengths, such as Ion Torrent or Nanopore. Similar to the Nanopore amplification of the entire genome described below, shotgun 
sequencing enables to obtain the entire genomic information in a given sample: taxonomic tracers from all areas and realms of life as well as functional genes.

(3) Nanopore sequencing technology: Nanopore has been little used in the field of cultural heritage and only two published studies have reported on the benefits of applying this state-of-the-art technology to valuable works of art. In the first study (Šoltys et al. 2019), Nanopore sequencing technology was used to study the microbiome of an eighteenth century wax seal stained with minium. The authors reported on the advantages of sequencing long DNA fragments, which allows sequencing of the almost complete $16 \mathrm{~S}$ rRNA gene as well as relatively long fragments (more than $600 \mathrm{bp}$ ) from the fungal ITS regions and 28S rRNA. However, the authors used target sequencing technology that did not allow for the relative proportion of different phylogenetic groups. In the second study (Piñar et al. 2020a), Nanopore sequencing technology was used for the first time together with a whole genome amplification (WGA) protocol to provide a rapid diagnosis of the biological infection in cultural artifacts. All advantages that this new technology can offer for metagenomic analyses starting from very low DNA concentrations were combined. To test the feasibility of this protocol on cultural assets, samples were taken from two eighteenth and nineteenth century oil paintings on canvas, one of which showed active fungal colonization, while the other had a cracked varnish surface (Fig. 3.4). The total number of reads obtained with Nanopore exceeded the 2,000,000 reads with an average read length of more than $4 \mathrm{~Kb}$ in both analyzed paintings. The resulting fast 5 data files were basecalled using the Nanopore GPU basecalling with GUPPY 3.0.3 on UBUNTU 16.04 (Nanopore Community Platform). Once the Fastq files were generated, the data were compared with databases using one of the available pipelines for data analyses of the Nanopore Community Platform, following the steps recommended by manufacturers. The selected workflow chosen was "What's in my pot" (WIMP). It is important to note that this platform offers a series of bioinformatics pipelines that are accessible to the end user and are userfriendly, allowing basic data analysis without the need for a bioinformatics expert. The results obtained with the WGA metagenomic approach proved to be successful for a rapid diagnosis of the microbial colonization of the two tested paintings showing different deterioration phenomena. Their microbiomes showed to be directly related to the conservation status of the paintings as well as with their restoration history (Piñar et al. 2020a).

Until now, the power of metagenomics has been largely tied to expensive and room-sized sequencing technologies, a large number of laboratory ancillary equipment and time-consuming workflows, making analysis far too complex and expensive for routine analysis by museums, collections, and restorers. Nanopore technology opens up new possibilities in this area of research and applied restoration:

- The basic equipment for this technology is the pocket-sized sequencer, combined with a laptop. 


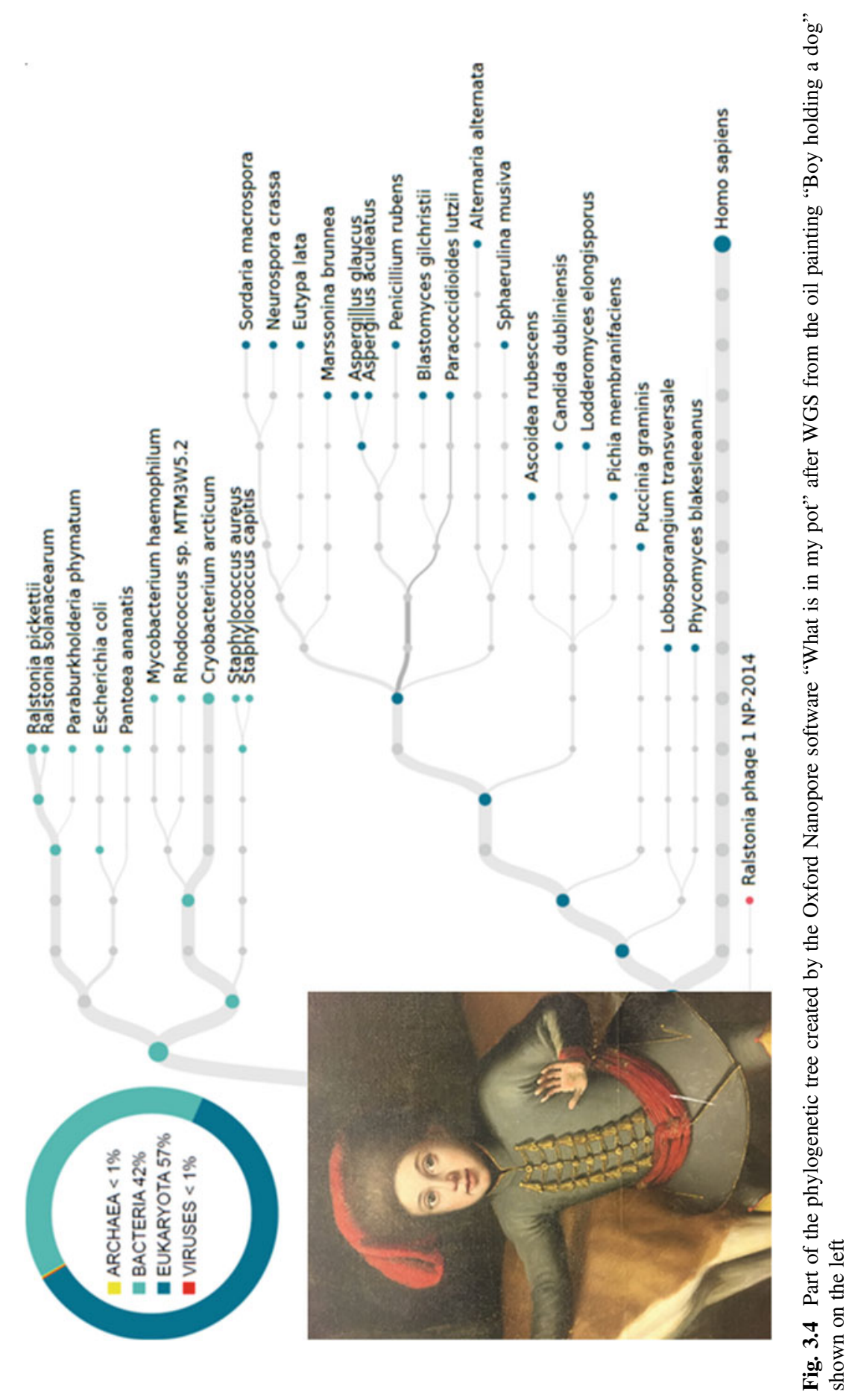


- The protocol, which uses whole genome amplification (WGA), is very efficient and allows the amplification of all phylogenetic groups at once, thus allowing the real metagenome and the relative proportions of the different phylogenetic kingdoms to be derived.

- As mentioned above, for data processing and the creation of phylogenetic treesincluding a quantitative representation of these-from the derived data, the company offers a toolbox that is open to all customers of the system. This enables the analysis and interpretation of the data without the involvement of a bioinformatician. However, it should be mentioned here that this only applies to the analysis of taxonomic units. If a targeted search for functional genes or other data mining is to be carried out, a bioinformatics approach is also required here.

As with any other sequencing technology, the user of Nanopore needs to have a background in microbial ecology and the materials under investigation in order to interpret the data correctly and summarize the microbial family tree for each individual sample as a reference data set for current and future comparisons.

In summary, the Nanopore sequencing technology offers several advantages in the field of cultural heritage compared to other NGS technologies, such as the length of the generated sequences, the taxonomic diversity reflecting the real proportions of all domains of life (Piñar et al. 2020a), the acceleration and simplification of the technical process, and the reduction of costs. In particular, the MinION device offers the possibility to perform in situ analyses. Instead of collecting samples and sequencing them in the laboratory, the miniature sequencers can be taken into the field and sequencing can be performed on site (Johnson et al. 2017). This last point can of course offer some additional advantages for practical reasons in cultural heritage research, such as in situ analysis in museums and depots, at archeological sites or in church interiors, if required. The Nanopore MinION technology offers a fast and affordable way to create microbial pedigrees of artifacts and is now available as a service for museums, restorers, art collections, auction houses, and even criminologists.

Based on the proven success in applying the Nanopore sequencing technology to valuable objects of cultural importance, a project has been launched to study the microbiomes of some of Leonardo Da Vinci's most emblematic drawings, as an example the Codex of the Flight (dated 1505-6). Depending on the available material, samples were represented by swabs, membranes, small particles of glues or impurities removed by conservators from the surfaces. The aim was to generate a specific microbiome from each investigated drawing in order to create a bio-archive to monitor the state of preservation of the drawings and thus be able to use them for possible comparisons in the future (Piñar et al. 2020b, in press).

To give the reader an impression of the steps required for WGA metagenome Nanopore sequencing, we have summarized them in Table 3.1. Details can be found from point 2 onwards (whole genome amplification) in the working instructions of the provider. 
Table 3.1 Basic protocol for whole genome amplification (WGA) and sequencing on objects of cultural heritage using the Nanopore technology ${ }^{\mathrm{a}}$

\section{DNA extraction}

-Extract DNA from samples (e.g., swabs, membranes, dust) using the FastDNA SPIN Kit for soil (MP Biomedicals, Illkrich, France) as recommended by the manufacturers.

-The DNA extracted from each single swab was pooled per sample to obtain a single microbiome from each object.

-Assess DNA concentrations by using the Qubit 2.0 fluorometer (Invitrogen Corporation), with the Qubit dsDNA HS Assay Kit.

\section{Whole Genome Amplification}

-Use the REPLI-g Midi Kit (Qiagen) using the innovative Multiple Displacement Amplification (MDA) technology. Perform reactions in a BioRad C1000 Thermal Cycler as follows:

-Load $5 \mu$ l template DNA (template DNA was $>10 \mathrm{pg}$ ) and $5 \mu \mathrm{l}$ Reconstituted Buffer DLB into a microcentrifuge tube and mix it by vortexing.

-Incubate the reaction tubes at room temperature $\left(15-25^{\circ} \mathrm{C}\right)$ for $3 \mathrm{~min}$.

-Add $10 \mu \mathrm{l}$ Stop solution to each reaction tube and mix by vortexing, resulting in $20 \mu \mathrm{l}$ denatured DNA.

-Prepare a $30 \mu 1$ master mix, containing per reaction $29 \mu 1$ REPLI-g Midi Reaction Buffer and $1 \mu 1$ REPLI-g Midi DNA polymerase, and add this to the $20 \mu$ denatured DNA prepared in the previous step.

-Incubate the reaction tubes at $30^{\circ} \mathrm{C}$ for $16 \mathrm{~h}$.

-Finally inactivate the REPLI-g Midi DNA Polymerase by heating the samples at $65^{\circ} \mathrm{C}$ for $3 \mathrm{~min}$. -After the WGA, assess the concentration of the amplified DNA with the Qubit 2.0 Fluorometer (Invitrogen Corporation) using the Qubit dsDNA BR Assay Kit.

\section{Library construction and quantification, template preparation and sequencing}

-Construct DNA libraries following the "Premium whole genome amplification protocol" available in the Oxford Nanopore community using the Ligation Sequencing kit 1D SQK-LSK109 and the Flow cell Priming kit EXP-FLP001 (Oxford Nanopore Technologies). All steps performed for library preparation comprise: (a) the digestion of the amplified DNA with T7 Endonuclease I (New England Biolabs) to remove DNA branching; (b) the preparation of the DNA ends for adapter attachment, using the NEBNext FFPE DNA repair mix (M6630) and the NEBNext End repair/dA-tailing Module (E7546) (New England Biolabs), and (c) the attachment of sequencing adapters supplied in the kit to the DNA ends, by using the NEBNext Quick Ligation Module (E6056) (New England Biolabs), were performed following the specifications of the manufacturers.

-After each step of library preparation, perform a clean-up step, using the AMPure XP beads (Agentcourt, Beckman) following the recommendations of the protocol.

-The DNA concentration was measured with the Qubit 2.0 Fluorometer (Invitrogen Corporation) using the Qubit dsDNA BR Assay Kit following each clean up step to assure the quality of the library.

-Once the library is finished, perform a quality control of the flow cell (SpotOn Flow cell Mk I R9 Version, FLO-MIN 106D) prior to starting the sequencing. The MinKNOW ${ }^{\mathrm{TM}}$ software was used to check the number of active pores in the flow cell.

-Finally, do the priming and the loading of the DNA library into the flow cell following exactly the recommendations of the manual supplied by the manufacturers!

-Start the sequencing run by connecting the Nanopore device (MinION) to a portable computer. -Start the software MinKNOW completing the steps recommended in the protocol, which comprises the selection of the local MinION, entering the Sample ID and the Flow cell ID to be used, and finally, the selection of the appropriate protocol script, allowing the script to run to completion. Runs were performed for $48 \mathrm{~h}$.

${ }^{a}$ The reader is kindly invited to follow the protocol given here. Please cite the following publication if you use the protocol for your scientific work or services: Piñar G, Poyntner C, Lopandic K, 
Tafer H, Sterflinger K. 2020. Rapid diagnosis of biological colonization in cultural artefacts using the MinION nanopore sequencing technology. International Biodeterioration and Biodegradation 148: 104908

\section{Transcriptomics and More -Omic and Meta-Omic Techniques for the Analysis of Cultural Heritage}

The DNA-based metagenomics and diversity studies described above have in common that they do not allow conclusions to be drawn about gene expression, so that the potential and actually expressed microbial functions cannot be identified. However, understanding the relationship between microbial diversity and functional processes is a fundamental question. Nowadays, there is a wealth of information on microbial diversity on cultural heritage objects (Sterflinger and Piñar 2013), which often reveal highly specialized microorganisms that can thrive in extreme environments. Nevertheless, the explicit functional and ecological role of individual taxa remains uncertain. Therefore, although the fundamental question: "Who is out there?" is already answered in part, the question "What do organisms do on and with the object?" is still largely unanswered.

The latter question could be answered mainly by using transcriptomics and metatranscriptomics. For the analysis of the transcriptome of a strain or a mixed microbial community, total ribosomal RNA-depleted or poly(A)+ RNA is isolated and converted into cDNA. A typical protocol involves the generation of cDNA of the first strand by random hexamer-primed reverse transcription and subsequent generation of cDNA of the second strand using RNase $\mathrm{H}$ and DNA polymerase. The cDNA is then fragmented and ligated to NGS adapters (McGettigan 2013).

In principle, this technology, if applied to whole communities, could be used to clarify what the microorganisms on the object do physiologically under certain conditions - such as temperature, humidity, exposure to light and weather-and whether they are capable of degrading a certain component of the object's material. This would be an absolute breakthrough on the way to the development of suitable measures that "inactivate" the potentially harmful microflora by controlling the environmental parameters without the need for toxic substances or expensive cleaning measures. The biggest challenge at present, however, is the quantity of sample material: the non-destructive methods used-simple removal using swabs or membranes-do not yet allow sufficient amounts of RNA to be obtained for existing technologies. There is a need for development here.

However, transcriptomic studies of individual biodeteriorative strains incubated under defined environmental conditions in the laboratory can provide initial insights into the ecology of individual organisms associated with a particular artifact. For example, comparative genomics and transcriptomics have been used to describe the adaptation strategies of the true halophilic fungus Aspergillus salisburgensis (Tafer et al. 2019). The fungus was originally isolated from a 3500-year-old wooden staircase in the salt mines of Hallstatt (Austria), a world cultural heritage site in Austria (Piñar et al. 2016). 
The development of high-throughput "omics" methods enables system approaches in which mixed microbial communities are studied as a single unit. Metagenomics, metatranscriptomics, metaproteomics, and metabolomics are used to determine the DNA sequences of the mixed community under investigation, the collectively transcribed RNA, the translated proteins, and the metabolites resulting from cellular processes. All data obtained can be used to identify metabolic pathways and cellular processes within an ecosystem (Kulski 2016). Therefore, the application of meta-omics analyses not only allows the identification of microbial groups in complex communities, but also allows the correlation of taxonomic groups with their ecological function and the observation of structural and functional shifts in communities caused by environmental changes. Meta-omics have the potential to perform in-depth studies on cultural assets in order to gain a deep understanding of the interactions between microorganisms and their substrates. In contrast to the successful application of metagenomics to cultural heritage, there are very few studies to date that demonstrate the success of applying proteomics in this field (Marvasi et al. 2019 and bibliography therein). However, proteomics has been successfully applied to cultural heritage to characterize protein-containing materials in ancient samples (Fiddyment et al. 2015; Vinciguerra et al. 2016). In the future, proteomics could help to analyze degrading enzymes such as proteases, cellulases, lipases, and other proteins with respect to their biodeterioration potential directly from the object of study. Also, the metabolome can provide information about destruction processes (Gutarowska et al. 2015). Conversely, the metabolome could possibly also be a key to the biological control of harmful microbes, since among the numerous primary and secondary metabolites, some of which are volatile organic compounds, there may also be those with antimicrobial effects (Campos and Zampieri 2019).

In conclusion, this review shows the potential of the molecular techniques available to date and the need for development to adapt many of these methodologies to the delicate field of cultural heritage. The further development of technological processes in molecular biology applied to heritage sciences will provide an in-depth understanding of the biodiversity and metabolic functions of the microbial communities that colonize culturally valuable objects. This will help in the first place to understand and mitigate biodeterioration, but also to answer many other interesting questions that may arise when handling valuable art objects.

\section{References}

Adamiak J, Otlewska A, Tafer H, Lopandic K, Gutarowska B, Sterflinger K, Piñar G (2018) First evaluation of the microbiome of built cultural heritage by using the Ion Torrent next generation sequencing platform. Int Biodeter Biodegr 131:11-18

Amann RI, Ludwig W, Schleifer KH (1995) Phylogenetic identification and in situ detection of individual microbial cells without cultivation. Microbiol Rev 59:143-169

Andrews S (2010) FastQC: a quality control tool for high throughput sequence data. Available online at: http://www.bioinformatics.babraham.ac.uk/projects/fastqc 
Branton D et al (2008) The potential and challenges of nanopore sequencing. Nat Biotechnol 26:1146-1153

Callahan BJ, Sankaran K, Fukuyama JA, McMurdie P, Holems SP (2016) Bioconductor workflow for microbiome data analysis: from raw reads to community analyses. F1000 Res 5:1492

Campos AI, Zampieri M (2019) Metabolomics-driven exploration of the chemical drug space to predict combination antimicrobial therapies. Mol Cell 74:1291-1303

Cutler NA, Oliver AE, Viles HA, Ahmad S, Whiteley AS (2013) The characterization of eukaryotic microbial communities on sandstone buildings in Belfast, UK, using TRFLP and 454 pyrosequencing. Int Biodeter Biodegr 82:124-133

Di Bonaventura MP, De Salle R, Bonacum J, Koestler RJ (2003) Tiffany's drawings, fungal spots and phylogenetic trees. In: Saiz-Jimenez C (ed) Molecular biology and cultural heritage. Balkema, Lisse, pp 131-148

Dobin A et al (2013) STAR: ultrafast universal RNA-seq aligner. Bioinformatics 29:15-21

Eid J et al (2009) Real-time DNA sequencing from single polymerase molecules. Science 323:133-138

Ettenauer JD, Jurado V, Pinar G, Miller AZ, Santner M, Saiz-Jimenez C, Sterflinger K (2014) Halophilic microorganisms are responsible for the rosy discolouration of saline environments in three historical buildings with mural paintings. PLoS One 9:1-12

Fiddyment $S$ et al (2015) Animal origin of 13th-century uterine vellum revealed using noninvasive peptide fingerprinting. Proc Natl Acad Sci USA 112:15066-15071

Fiddyment S, Teasdale MD, Vnouček J, Lévêque E, Binois A, Collins MJ (2019) So you want to do biocodicology? A field guide to the biological analysis of parchment. Herit Sci 7:35

Goodwin S, McPherson JD, McCombie WR (2016) Coming of age: ten years of next generation sequencing technologies. Nat Rev Genet 17:333-351

Gutarowska B et al (2015) Metabolomic and high-throughput sequencing analysis-modern approach for the assessment of biodeterioration of materials from historic buildings. Front Microbiol 6:979

Huang Z, Zhao F, Li Y, Zhang J, Feng Y (2017) Variations in the bacterial community compositions at different sites in the tomb of Emperor Yang of the Sui Dynasty. Microbiol Res 196:26-33

Johnson SS, Zaikova E, Goerlitz DS, Bai Y, Tighe SW (2017) Real-time DNA sequencing in the Antarctic Dry Valleys using the Oxford Nanopore sequencer. J Biomol Technol 28:2-7

Jroundi F, Gonzalez-Muñoz MT, Sterflinger K, Piñar G (2015) Molecular tools for monitoring the ecological sustainability of a stone bio-consolidation treatment at the Royal Chapel, Granada. PLoS One 10:e132465

Kalvari I, Argasinska J, Quinones-Olvera N, Nawrocki EP, Rivas E, Eddy SR, Bateman A, Finn RD, Petrov AI (2018) Rfam 13.0: shifting to a genome-centric resource for non-coding RNA families. Nucl Acids Res 46:D335-D342

Koestler RJ, Koestler VH, Charola AE, Nieto-Fernandez FE (2003) Art, biology, and conservation: biodeterioration of works of art. The Metropolitan Museum of Art, New York

Kulski JK (2016) Next-generation sequencing - an overview of the history, tools, and "omic" applications. In: Kulski JK (ed) Next generation sequencing - advances, applications and challenges. INTECH, London, eBook (PDF) ISBN: 978-953-51-5419-8

Laiz L, Piñar G, Lubitz W, Saiz-Jimenez C (2003) Monitoring the colonization of monuments by bacteria: cultivation versus molecular methods. Environ Microbiol 5:72-74

Martin M (2011) Cutadapt removes adapter sequences from high-throughput sequencing reads. EMBnet J 17:10-12

Marvasi M, Cavalieri D, Mastromei G, Casaccia A, Perito B (2019) Omics technologies for an in-depth investigation of biodeterioration of cultural heritage. Int Biodeter Biodegrad 144:104736

McGettigan PA (2013) Transcriptomics in the RNA-seq era. Curr Opi Chem Biol 17:4-11

Metzker ML (2010) Sequencing technologies - the next generation. Nat Rev Genet 11:31-46 
Miklas H, Sablatnig R, Brenner S, Schreiner M, Cappa F, Piñar G, Sterflinger K (2019) The Vienna glagolotic projects: past and present. In: Stankovska P, Derganc A, Sivic-Dular A, Rajkko Nahtigal in 100 let slavistike na Univerzi v Ljubljani - Monografija ob 100. oblenici nastanka Oddelka za slavistiko Filozofske fakultete UL, 63-80; Slavica Slovenica, Ljubljana, pp 63-80. Please, clarify this reference. Editor, publisher, city, etc

Nawrocki EP, Eddy SR (2013) Infernal 1.1: 100-fold faster RNA homology searches. Bioinformatics 29:2933-2935

Ondov BD, Bergman NH, Phillippy AM (2011) Interactive metagenomic visualization in a Web browser. BMC Bioinformatics 12:385

Piñar G, Dalnodar D, Voitl C, Reschreiter H, Sterflinger K (2016) Biodeterioration risk threatens the 3100 year old staircase of Hallstatt (Austria): possible involvement of halophilic microorganisms. PLoS One 11:e0148279

Piñar G, Poyntner C, Tafer H, Sterflinger K (2019) A time travel story: metagenomic analyses decipher the unknown geographical shift and the storage history of possibly smuggled antique marble statues. Ann Microbiol 69:1001-1021

Piñar G, Poyntner C, Lopandic K, Tafer H, Sterflinger K (2020a) Rapid diagnosis of biological colonization in cultural artefacts using the MinION nanopore sequencing technology. Int Biodeter Biodegr 148:104908

Piñar G, Sclocchi MC, Sebastiani ML, Sterflinger K (2020b) The "Biological Pedigrees" of some emblematic Leonardo Da Vinci's objects. Gangemi Editore, Rome. in press

Piñar G, Tafer H, Schreiner M, Miklas H, Sterflinger K (2020c) Decoding the biological information contained in two ancient Slavonic parchment codices: an added historical value. Environ Microbiol. In press. https://doi.org/10.1111/1462-2920.15064

Pinzari F, Montanari M, Michaelsen A, Piñar G (2010) Analytical protocols for the assessment of biological dam-age in historical documents. Coalit Newslett 19:6-13

Rölleke S, Muyzer WG, Wanner C, Lubitz W (1999) Identification of bacteria in a biodegraded wall painting by denaturing gradient gel electrophoresis. Appl Environ Microbiol 62:2059-2065

Rosado T, Mirão J, Candeias A, Caldeira AT (2014) Microbial communities analysis assessed by pyrosequening - a new approach applied to conservation state studies of mural paintings. Anal Bioanal Chem 406:887-895

Rothberg J et al (2011) An integrated semiconductor device enabling non-optical genome sequencing. Nature 475:348-352

Saiz-Jimenez C (ed) (2003) Molecular biology and cultural heritage. Balkema, Lisse

Schabereiter-Gurtner C, Piñar G, Lubitz W, Rölleke S (2001) An advanced molecular strategy to identify bacterial communities on art objects. J Microbiol Methods 45:77-87

Schabereiter-Gurtner C, Saiz-Jimenez C, Piñar G, Lubitz W, Rölleke S (2002a) Phylogenetic 16S rRNA analysis reveals the presence of complex and partly unknown bacterial communities in Tito Bustillo cave, Spain, and on its Palaeolithic paintings. Environ Microbiol 4:392-400

Schabereiter-Gurtner C, Saiz-Jimenez C, Piñar G, Lubitz W, Rölleke S (2002b) Altamira cave Paleolithic paintings harbor partly unknown bacterial communities. FEMS Microbiol Lett 211:7-11

Schadt EE, Turner S, Kasarkskis A (2010) A window into third-generation sequencing. Human Mol Genet 19:227-240

Šoltys K, Planý M, Biocca P, Vianello V, Bučková M, Puškárov A, Sclocchi MC, Colaizzi P, Bicchieri M, Pangallo D, Pinzari F (2019) Lead soaps formation and biodiversity in a XVIII Century wax seal coloured with minium. Environ Microbiol 22(4):1517-1534

Sterflinger K, Piñar G (2013) Microbial deterioration of cultural heritage and works of art — tilting at windmills? Appl Microbiol Biotechnol 97:9637-9646

Sterflinger K, De Baere R, de Hoog GS, De Wachter R, Krumbein WE, Haase G (1997) Coniosporium perforans and C. apollinis, two new rock-inhabiting fungi isolated from marble in the Sanctuary of Delos (Cyclades, Greece). Anton Leeuw 2: 349-363 
Sterflinger K, Little B, Piñar G, Pinzari F, De los Rios A, Gu JD (2018a) Future directions and challenges in biodeterioration research on historic materials and cultural properties. Int Biodeter Biodegr 129:10-12

Sterflinger K, Voitl C, Lopandic K, Piñar G, Tafer H (2018b) Big sound and extreme fungixerophilic, halotolerant Aspergilli and Penicillia with low optimal temperature as invaders of historic pipe organs. Life 8:22

Tafer H, Poyntner C, Lopandic K, Sterflinger K, Piñar G (2019) Back to the salt mines: Genome and transcriptome comparisons of the halophilic fungus Aspergillus salisburgensis and its halotolerant relative Aspergillus sclerotialis. Genes 10:381

Truong DT, Franzosa E, Tickle TL, Scholz M, Weingart G, Pasolli E et al (2015) MetaPhlAn2 for enhanced metagenomic taxonomic profiling. Nat Methods 12:902-903

Vinciguerra R, De Chiaro A, Pucci P, Marino G, Biroloa L (2016) Proteomic strategies for cultural heritage: From bones to paintings. Microchem J 126:341-348

Völkerding KV, Dames SA, Durtschi JD (2009) Next-generation sequencing: from basic research to diagnostics. Clin Chem 55:641-658

Vuissoz A, Worobeya M, Odegaard N, Bunce M, Machadoa CA, Lynner N, Peacocke E, Thomas M, Gilbert P (2007) The survival of PCR-amplifiable DNA in cow leather. J Archaeol Sci 34:823-829

Wieser M, Worliczek HL, Kämpfer P, Busse HJ (2005) Bacillus herbersteinensis sp. nov. Int J Syst Evol Microbiol 55:2119-2123

Wiesinger R (2018) Material stability of art and cultural heritage, Habilitation Thesis, Institut für Naturwissenschaften und Technologie in der Kunst, Akademie der Bildenden Künste Wien

Wingett SW, Andrews S (2018) FastQ Screen: a tool for multi-genome mapping and quality control. F1000 Res 7:1338

Open Access This chapter is licensed under the terms of the Creative Commons Attribution 4.0 International License (http://creativecommons.org/licenses/by/4.0/), which permits use, sharing, adaptation, distribution and reproduction in any medium or format, as long as you give appropriate credit to the original author(s) and the source, provide a link to the Creative Commons license and indicate if changes were made.

The images or other third party material in this chapter are included in the chapter's Creative Commons license, unless indicated otherwise in a credit line to the material. If material is not included in the chapter's Creative Commons license and your intended use is not permitted by statutory regulation or exceeds the permitted use, you will need to obtain permission directly from the copyright holder.

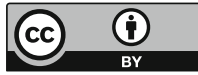

